$\begin{array}{cc}\text { ACADEMIA ROMÂNĂ } & \text { Rev. Roum. Chim., } \\ \text { Revue Roumaine de Chimie } & \text { D5(10), 899-907 } \\ \text { http://web.icf.ro/rrch/ } & \text { DoI: 10.33224/rrch.2020.65.10.05 }\end{array}$

\title{
CHEMICAL COMPOSITION AND ANTIMICROBIAL ACTIVITY OF ESSENTIAL OIL OF CITRUS SINENSIS: INTERACTION WITH AMPICILLIN AND FLUCONAZOLE
}

\author{
Elif Ayşe Erdoğan ELIUZZ ${ }^{\mathrm{a}, *}$, Erdal YABALAK ${ }^{\mathrm{b}, *}$ and Yusuf SICAK ${ }^{\mathrm{c}}$ \\ ${ }^{a}$ Mersin University, Technical Sciences Vocational School, Department of Food Technology, TR-33343, Mersin, Turkey \\ ${ }^{\mathrm{b}}$ Mersin University, Faculty of Arts and Science, Department of Chemistry, Çiftlikköy Campus, TR-33343, Mersin, Turkey \\ ${ }^{c}$ Muğla S1tkı Koçman Universit, Vocational School of Koycegiz, Department of Plant and Animal Production, Muğla, Turkey
}

Received April 1, 2020

In the present study, the interactions of essential oil (EO) of Citrus sinensis L. Osbeck with two antibiotics (ampicillin and fluconazole), which are commonly used in the treatment of infections, were investigated. $C$. sinensis was hydrodistilled and the chemical composition of the obtained essential oil was identified by GC-MS (Gas Chromatography-Mass Spectrometry) analyses. The most representative compound of all obtained 18 compounds was $d$-limonene followed by the other major components such as linalool, $\alpha$-terpineol, $\beta$-myrcene. The MICs (Minimum Inhibitory Concentration) of C. sinensis essential oil were $152.06 \mathrm{mg} / \mathrm{mL}, 20 \mathrm{mg} / \mathrm{mL}, 54.41 \mathrm{mg} / \mathrm{mL}$ and the IZs (Inhibition Zone) were noted as $3.4 \mathrm{~mm}, 3.3 \mathrm{~mm}, 8.3 \mathrm{~mm}$ for E. coli, $S$. aureus for $C$. albicans, respectively. Antimicrobial performance of antibiotics in combinations with the essential oil on Escherichia coli, Staphylococcus aureus and Candida albicans were determined using antimicrobial checkerboard method. According to this model, antagonist effect was observed as $14.29 \%, 57.14 \%$ and $0 \%$ for $S$. aureus, E. coli and C. albicans, respectively. As a result, the use of $C$. sinensis essential oil with antibiotics can be seen as a disadvantage as it may slow the effect of antibiotics. On the contrary, in another case, the using of $C$. sinensis essential oil with antibiotics may cause to delaying the resistance mechanisms of bacteria and turn of antagonism to advantage in clinical applications.

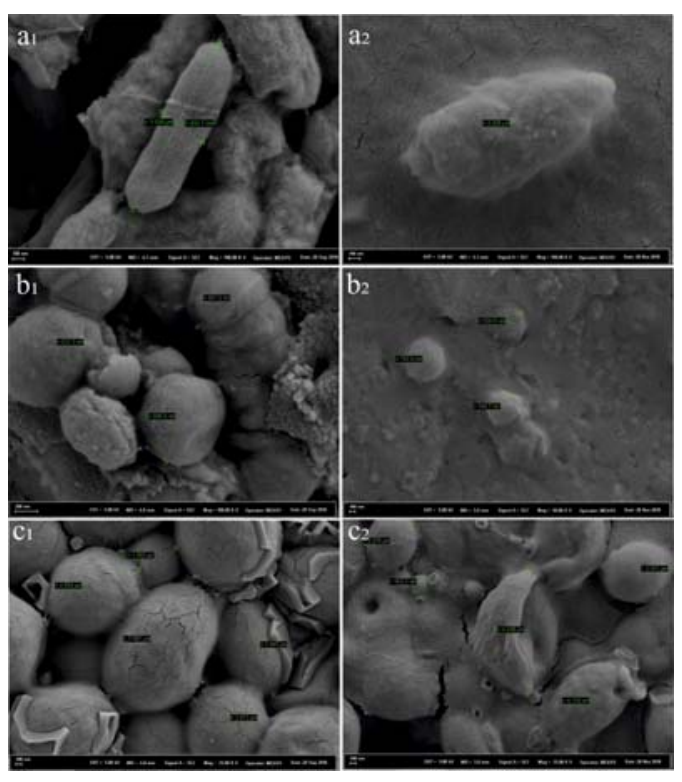

\section{INTRODUCTION}

Citrus sinensis ( $C$. sinensis) is the botanical name of a well-known fruit, orange which belongs to the Rutaceae family. ${ }^{1}$ Citrus varieties including orange, mandarins, kumquat and limes are the most widespread fruits with approximately 120000 thousand tons of global production. ${ }^{2,3}$ The largest citrus grown were belonged to $C$. sinensis with
$70 \%$ of the total annual production and spread over temperate climatic zones. It is commonly 9-10 meters tall with large spines on branches and it has narrowly winged-petioles more than $3 \mathrm{~mm}$ wide. Leaves also vary from elliptical, bluntly toothed, oblong to oval, and especially their odour is characteristic because of the presence of copious oil leaves. ${ }^{4}$ The peel, leaves, roots, fruits and juice of $C$. sinensis is the rich sources of volatile

\footnotetext{
*Corresponding authors: eliferdogan81@gmail.com or yabalakerdal@gmail.com
} 
compounds which provide great pharmacological importance to this plant. ${ }^{5}$ The essential oil of $C$. sinensis possesses antimicrobial activities against most prevalent species of gram-positive and gramnegative bacteria and fungal pathogens that are liable for many severe infections. ${ }^{6}$

Antibiotics are among the most powerful tools to deal with infections. However, microorganisms have a remarkable genetic ability to develop resistance to antimicrobial compounds. ${ }^{7}$ Recent advances in medical biotechnology have not been able to handle the rapid emergence of resistant microorganisms which resulted in a considerable public health threat influencing humans worldwide. ${ }^{8}$

Recent works suggest that the different types of synergic or antagonistic interactions have contributed considerably to the understanding of drug resistance. Although the synergistic effect is beneficial in rapid treatment, it has been stated that it causes the development of drug-resistance. In particular, a growing number of laboratory studies indicate that antagonistic drug combinations merit further study as therapeutic options; some researchers emphasize that antagonism among antibiotics will support the development of treatment strategies specifically aimed at delaying the emergence of resistance. ${ }^{9,10}$

Therefore, there is a need for the development of novel agents or combinations to be used as effective antimicrobial agents. Due to the antimicrobial effect of essential oils, their use in combination with antibiotics might lead to new products with enhanced antimicrobial efficiency. Despite the proven antimicrobial activity of essential oil of $C$. sinensis ( $C s \mathrm{EO}$ ), no study on the antimicrobial effectiveness of $C s \mathrm{EO}$ in combination with ampicillin or fluconazole has been reported. Hence, the present study aimed to assess the susceptibility of E. coli, S. aureus and C. albicans to single and combinations of $C s \mathrm{EO}$ to detect a synergistic effect (SynE), indifferent effect (IndE) and/or antagonistic effect (AntE) and to correlate the chemical profile of the oil to the antimicrobial activity. Besides, the damaged parts of microorganisms' cell surfaces were determined by SEM (Scanning Electron Microscopy) at the end of the 24-h incubation with $C s E O$. Thus, it was examined in nanoscale how the subjected microorganisms were damaged by the synergistic effect of antibiotics and $C s \mathrm{EO}$.

Considering the potential effects of the compounds that exist in the essential oils on human health, and the fact that the components they contain have fewer side effects than the synthetic counterparts, determining the chemical composition of essential oils is of utmost importance. Thus, the determination of the composition of essential oil of C. sinensis and the identification of the effects of the identified compounds extended the scope of this study.

\section{EXPERIMENTAL}

\section{Materials and Instruments}

Chemical analysis of $C$. sinensis essential oil was performed using Agilent brand GC-MS. Mueller Hinton Agar (MHA), Mueller Hinton Broth (MHB), Sabouraud Dextrose Broth (SDB), Triptic Soy Broth (TSB) were supplied from Merck (Darmstadt, Germany). Ampicillin (AMP) and Fluconazole (FLC) and Dimethyl Sulfoxide (DMSO) were purchased from Sigma. E. coli (ATCC 25293), S. aureus and C. albicans were purchased from Refik Saydam Hifzıssihha Centre (Ankara/Turkey). The 96-well microtiter plates and sterile Petri were purchased from Labkon Ltd. Eliza spectrophotometer (Thermo Scientific, MULTISKAN GO) was used for antimicrobial measurements and the microscopic imaging, the samples were dried using critical point dryer, EMITECH K850 and were platin covered by spraying Quorum 150R ES and examined with the SEM (Scanning Electron Microscopy ZEISS SUPRA 55).

\section{Plant Material and Essential Oil Extraction}

C. sinensis were collected from Köyceğiz region of Muğla, Turkey in 2017. It was identified and confirmed by comparing it with the specimen located at the Herbarium of Biology, Faculty of Science, A Application and Research Center by GC-MS 7890A-(5975C inert MSD) instrument equipped with an Agilent 19091S-433 column (30m X $250 \mu \mathrm{m}$ film $X 0.25 \mu \mathrm{m}$ thickness). Helium was used as a carrier gas. The sample was eluted for 64 minutes of retention time using the following temperature programme. After the initial temperature of $60^{\circ} \mathrm{C}$ for $5 \mathrm{~min}$, it was gradually raised to $150^{\circ} \mathrm{C}$ by an increase of $3^{\circ} \mathrm{C} / \mathrm{min}$ for $2 \mathrm{~min}$, then by $3^{\circ} \mathrm{C} / \mathrm{min}$ to $200^{\circ} \mathrm{C}$ and by $4^{\circ} \mathrm{C} / \mathrm{min}$ to $240^{\circ} \mathrm{C}$. Characterization of $C s \mathrm{EO}$ components was performed based on the mass spectra library (Wiley Registry 9th/NIST 2011 database, W9N11.L).

\section{Antimicrobial Screening}

The inoculums of E. coli (ATCC 25293), S. aureus and C. albicans were prepared in $4 \mathrm{~mL}$ TSB for bacteria, $4 \mathrm{~mL}$ SDB for yeasts and incubated at $37{ }^{\circ} \mathrm{C}$, overnight. After 24 hours, the culture suspensions were adjusted to $0.5 \mathrm{McFarland}$ Standard Turbidity and stored at $+4{ }^{\circ} \mathrm{C}$ until further use.

\subsection{Disc Diffusion Assay}

Microorganism cultures were spread onto MHA plates. Paper discs (6 $\mathrm{mm}$ in diameter) were impregnated on the agar to load $15 \mu \mathrm{L}$ of $\mathrm{CsEO}$ (pure) and incubated at $37{ }^{\circ} \mathrm{C}$ for $24 \mathrm{hrs}$. The results were recorded in the zones of growth inhibition surrounding the disc using a digital calliper. Ampicillin and Fluconazole were used as positive controls. 


\subsection{Spectrophotometric Checkerboard Microdilution}

The $50 \mu \mathrm{L}$ of MHB medium were added into 96-well microtiter plates. Two-fold serial dilutions of $50 \mu \mathrm{L} C s \mathrm{EO}$ solution $(3.5 \mathrm{mg} / \mathrm{mL}$ in $10 \% \mathrm{DMSO})$ was made (A1-H1) on the y-axis along of chequerdoard plate. Two-fold serial dilutions of $50 \mu \mathrm{L}$ antibiotic dilution (starting concentration; AMP: $128 \mu \mathrm{g} /$ and FLC: $5128 \mu \mathrm{g} / \mathrm{mL}$ ) was made $\mathrm{x}$-axis along from 2nd to 10th columns and $C s E O$ solution (single concentration: $100,50,25,12.5,6.25,3.12,1.56 \mu 1)$ was added to each line to make fraction and obtain the FIC final concentrations. Columns 11 and 12 were used as negative and positive controls, respectively (Figure 1). Finally, $5 \mu \mathrm{L}$ culture of microorganisms were inoculated on all wells except negative control. All plates were incubated at $37{ }^{\circ} \mathrm{C}$ for 24 hours, the growth (turbidity) was measured at $600 \mathrm{~nm}$ and $415 \mathrm{~nm}$ for bacteria and yeast, respectively. For MIC analysis, the optical density was read both before incubation, $t_{0}$, and after 24 hours-incubation, $t_{24}$. For each plate, MIC was calculated using the regression curve. The OD for each replicate at $t_{0}$ was subtracted from the OD for each replicate at $t_{24}$.

$$
\begin{gathered}
\text { Growth }(\%)=\left(\frac{O D_{\text {test }}}{O D_{\text {control }}}\right) \times 100 \\
\text { Inhibition }(\%)=\left(1-\frac{O D_{\text {test well }}}{O D_{\text {corresponding control well }}}\right) \times 100
\end{gathered}
$$

For each row of the 96-well plate, the lowest concentration of test material (MIC) which results in $99.9 \%$ inhibition of growth were calculated using Eq. 1 and Eq. 2

$$
\Sigma \mathrm{FIC}=\mathrm{FIC}_{\mathrm{A}(\text { antibiotic })}+\mathrm{FIC}_{\mathrm{C}(\text { C. sinensis } \mathrm{EO})}=\left(\mathrm{MIC}_{(\mathrm{A}+\mathrm{C}) / \mathrm{A}}\right)+\left(\mathrm{MIC}_{(\mathrm{A}+\mathrm{C}) / \mathrm{C}}\right)
$$

where $\mathrm{MIC}_{\mathrm{A}}$ and $\mathrm{MIC}_{\mathrm{C}}$, present the MICs of antibiotics and the $C s \mathrm{EO}$ alone, in all wells corresponding to a MIC. ${ }^{11}$ Fractional Inhibitory Concentration Index (FICI) were interpreted following the conventional model suggested by
Odds; According to that, a synergistic effect (SynE) is observed when FICI value $\leq 0.5$; an indifferent effect (IndE) when $0.5<\mathrm{FICI} \leq 4$ and an antagonistic effect (AntE) when FICI value $>4 .^{12}$

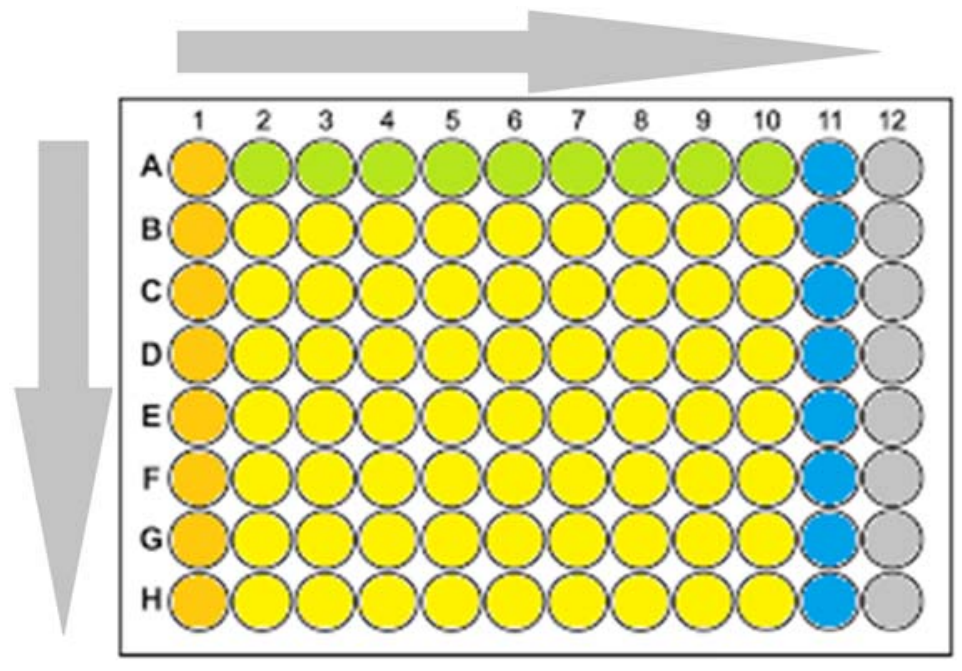

Fig. 1 - Design of the FICI experiment on a multiwall (ELISA) plate; orange wells: $C s \mathrm{EO}$ dilution and microorganism; green wells: antibiotic dilution and microorganism; yellow wells: antibiotic and $C s \mathrm{EO}$ combinations and microorganism; blue wells: bacteria growth control; gray wells: media growth control.

\section{Cell Surface Analysis Using SEM}

After 24 hours incubation of $C s \mathrm{EO}$ with E. coli, S. aureus and $C$. albicans, cultures in MIC wells were collected and centrifuged in a $1.5 \mathrm{~mL}$ Eppendorf at $15000 \mathrm{rpm}$ for $5 \mathrm{~min}$ and the pellet was resuspended in $1.5 \mathrm{~mL}$ of $2.5 \%$ glutaraldehyde solution for $4 \mathrm{~h}$. Then the samples were dehydrated by successive 10 -min incubations in 35\%, 50\%, 70\%, 95\%, 100\% ethanol and allowed to dry on aluminium foil. Finally, before microscopic imaging, the specimens were dried using a critical point dryer. The samples were platinum covered by spraying (Quorum 150R ES) and examined with the SEM. ${ }^{13}$ 


\section{Statistical Analysis}

Statistical analyses and significance were measured by LSD test and Tamhane's T2 in one-way analysis of variance for MICs using SPSS 25. Differences were considered significant at $p \leq 0.05$.

\section{RESULTS AND DISCUSSION}

\section{Chemical composition}

The components of the essential oil of C. sinensis were determined by GC-MS analysis using mass spectral libraries. Kováts indices (KI), which is a frequently used method to prevent the effect of GC analysis conditions on retention times, were calculated for each compound and obtained indices were compared to the ones reported in literature. $^{14-16}$ In total, 18 compounds were identified with the quality values above $80 \%$ and were given in Table 1 along with their values such as retention time $\left(\mathrm{t}_{\mathrm{r}}\right)$, peak area $(\%)$, peak quality $(\%), \mathrm{KI}$ and Kováts index obtained from literature (RIL). In this manner, the obtained compounds were evaluated for their bioactivity properties such as antimicrobial activities in the following.

$\alpha$-Pinene was obtained by $0.32 \%$ of peak area with $94 \%$ of the peak quality and the calculated KI was in good compatibility with the reported one. ${ }^{17}$ Also, Vujisić et al. reported that $\alpha$-pinene was found to be $1.5 \%$ in the essential oil of A. ruthenic. ${ }^{17}$ Saraglou et al. detected $\alpha$-pinene and sabinene as the components of essential oils of Hypericum species in their work, in which they specified the antimicrobial activity of the mentioned essential oils. ${ }^{18} \beta$-myrcene was detected at a peak area of 1.42 with $93 \%$ peak quality. It was observed that the calculated KI value of $\beta$-myrcene (987.67) was quite consistent with the value in literature (992). ${ }^{19,20}$ In the reported works, $\beta$-myrcene, $\alpha$-pinene, sabinene, linalool, 4-terpineol, $\alpha$-terpineol and carvacrol were found in the essential oils of some Thymus and Origanum species in different levels. The total peak area of these compounds was found as $6.08 \%$ in this work. They mentioned that the existence of the mentioned compounds along with the others and their levels may have affected the antimicrobial and antioxidant activities. ${ }^{20,21}$

The most remarkable components found in the essential oil of $C$. sinensis is undoubtedly $d$-limonene, which was found at a peak ratio of $88.9 \%$ in this study. $d$-Limonene was followed by linalool $(2.02 \%), \quad \alpha$-terpineol $(1.43 \%), \quad$ and $\beta$-myrcene (1.42\%). Similarly, the main compounds in the essential oil of $C$. sinensis peel were reported to be limonene (96.62\%), $\beta$-myrcene $(1.72 \%)$, $\beta$-pinene $(0.53 \%), \alpha$-pinene $(0.47 \%)$, citral Z $(0.31 \%)$ and citral E $(0.34 \%){ }^{22}$ Singh et al. depicted that d-limonene $(90.66 \%)$, linalyl acetate $(2.80 \%)$ and $\beta$-myrcene (1.71\%) were the major components in $C$. sinensis oil according to GC-MS analyses. ${ }^{23}$ Furthermore, $d$-limonene and $d$-carvone have strong bioactivity profiles as stated by Aggarwal et al. in their research on antimicrobial activity of the enantiomers of these compounds found in the essential oils of Mentha spicate and Anethum sowa. ${ }^{22}$

Table 1

Chemical composition of $C$. sinensis essential oil

\begin{tabular}{cccccccccc}
\hline C. No & Compound Name & $\begin{array}{c}\text { Chemical } \\
\text { Formula }\end{array}$ & $\begin{array}{c}\text { Molecula } \\
\mathrm{r} \text { Weight } \\
(\mathrm{g} / \mathrm{mol})\end{array}$ & $\mathrm{t}_{\mathrm{r}}(\mathrm{min})$ & $\begin{array}{c}\text { Peak } \\
\text { Area } \\
(\%)\end{array}$ & $\begin{array}{c}\text { Qualit } \\
\mathrm{y}(\%)\end{array}$ & KI & RIL & Ref. No \\
\hline 1 & $\alpha$-Pinene & $\mathrm{C}_{10} \mathrm{H}_{16}$ & 136.24 & 9.30 & 0.32 & 94 & 886.41 & 890 & 17 \\
2 & Sabinene & $\mathrm{C}_{10} \mathrm{H}_{16}$ & 136.23 & 11.00 & 0.21 & 96 & 958.33 & 953 & 17 \\
3 & $\beta$-myrcene & $\mathrm{C}_{10} \mathrm{H}_{16}$ & 136.23 & 11.76 & 1.42 & 93 & 987.67 & 992 & 19 \\
4 & octanal & $\mathrm{C}_{8} \mathrm{H}_{16} \mathrm{O}$ & 128.21 & 12.36 & 0.28 & 80 & 990.33 & 993 & 17 \\
5 & $\alpha$-limonene & $\mathrm{C}_{10} \mathrm{H}_{16}$ & 136.24 & 13.96 & 88.9 & 98 & 1017.71 & 1018 & 17 \\
6 & 1-octanol & $\mathrm{C}_{10} \mathrm{H}_{18} \mathrm{O}$ & 130.23 & 15.64 & 0.32 & 90 & 1072.63 & 1065 & 17 \\
7 & Linalool & $\mathrm{C}_{10} \mathrm{H}_{18} \mathrm{O}$ & 154.25 & 16.99 & 2.02 & 97 & 1107.72 & 1104 & 21 \\
8 & citronellal & $\mathrm{C}_{10} \mathrm{H}_{18} \mathrm{O}$ & 154.14 & 19.43 & 0.13 & 97 & 1155.96 & 1158 & 19 \\
9 & 4-terpineol & $\mathrm{C}_{10} \mathrm{H}_{18} \mathrm{O}$ & 154.25 & 20.61 & 0.52 & 96 & 1180.58 & 1177 & 21 \\
10 & $\alpha$-Terpineol & $\mathrm{C}_{10} \mathrm{H}_{18} \mathrm{O}$ & 154.25 & 21.29 & 1.43 & 91 & 1192.62 & 1190 & 21 \\
11 & Decanal & $\mathrm{C}_{10} \mathrm{H}_{20} \mathrm{O}$ & 156.20 & 21.82 & 0.37 & 91 & 1194.37 & 1198 & 17 \\
12 & trans-(+)-carveol & $\mathrm{C}_{10} \mathrm{H}_{16} \mathrm{O}$ & 152.23 & 22.63 & 0.31 & 96 & 1214.64 & 1212 & 17 \\
\hline
\end{tabular}


Table 1 (continued)

\begin{tabular}{lcllllllll}
\hline 13 & Nerol & $\mathrm{C}_{10} \mathrm{H}_{18} \mathrm{O}$ & 154.25 & 23.02 & 0.62 & 86 & 1227.90 & 1229 & 25 \\
14 & Z-citral & $\mathrm{C}_{10} \mathrm{H}_{16} \mathrm{O}$ & 152.24 & 23.55 & 0.46 & 90 & 1236.80 & 1238 & 26 \\
15 & d-carvone & $\mathrm{C}_{10} \mathrm{H}_{14} \mathrm{O}$ & 150.22 & 23.73 & 0.13 & 97 & 1239.54 & 1241 & 25 \\
16 & Geraniol & $\mathrm{C}_{10} \mathrm{H}_{18} \mathrm{O}$ & 154.25 & 24.22 & 0.32 & 96 & 1270.63 & 1267 & 26 \\
17 & Carvacrol & $\mathrm{C}_{10} \mathrm{H}_{14} \mathrm{O}$ & 150.22 & 26.46 & 0.16 & 94 & 1298.65 & 1299 & 26 \\
18 & $p$-vinylguaiacol & $\mathrm{C}_{9} \mathrm{H}_{10} \mathrm{O}_{2}$ & 150.18 & 26.94 & 0.26 & 96 & 1311.34 & 1315 & 27 \\
\hline
\end{tabular}

RIL: Literature Kováts index, RI: Calculated Kováts index

$\alpha$-Pinene, sabinene, myrcene, linalool, 4-terpineol, $\alpha$-terpineol, citronellal, nerol, geraniol and carvacrol were detected in the composition of eleven essential oils from the different origin by Sacchetti et $a .^{28}$ They investigated the effects of these essential oils against some bacterial strains. Linalool and geraniol were reported to be found in the composition of essential oil of $C$. citratus, $\alpha$-pinene, nerol was in the T. citriodorus and myrcene were in the both of them, which were reported as the most effective species against the tested strains. ${ }^{28}$ Citral may have the same efficacy as geraniol considering the isomeric structure of them. ${ }^{28}$ Besides, the obtained KI values of $\beta$-myrcene, 4-terpineol, $\alpha$-Terpineol, nerol and carvacrol were in good accordance with the ones reported by Sacchetti et al. ${ }^{28}$ Küçük et al. reported the moderate antimicrobial activity of the essential oil of Teucrium chamaedrys L. subsp. chamaedrys, Teucrium orientale var. puberulens, and Teucrium chamaedrys L. subsp. lydium against Gram- positive and Gram-negative bacteria. ${ }^{29}$ Decanal and $p$-vinylguaiacol, which were found in the essential oil of $C$. sinensis in this work, were the compounds detected in the mentioned essential oils by Küçük et $a l .{ }^{29}$

\section{Antimicrobial Activity and Antagonism}

In this study, according to both disc diffusion and broth microdilution method, E. coli, S. aureus and $C$. albicans were found to be rather sensitive to $C$. sinensis EO (Table 2). In the disc diffusion method, CsEO strongly inhibited E. coli, S. aureus and $C$. albicans. The inhibition zones were noted as $3.4 \mathrm{~mm}$ for E. coli, $3.3 \mathrm{~mm}$ for $S$. aureus, and $8.3 \mathrm{~mm}$ for C. albicans. It was 6.8 and $9.9 \mathrm{~mm}$ for E. coli and $S$. aureus in AMP, $27 \mathrm{~mm}$ for C. albicans in FLC as a positive control, respectively (Figure 2).
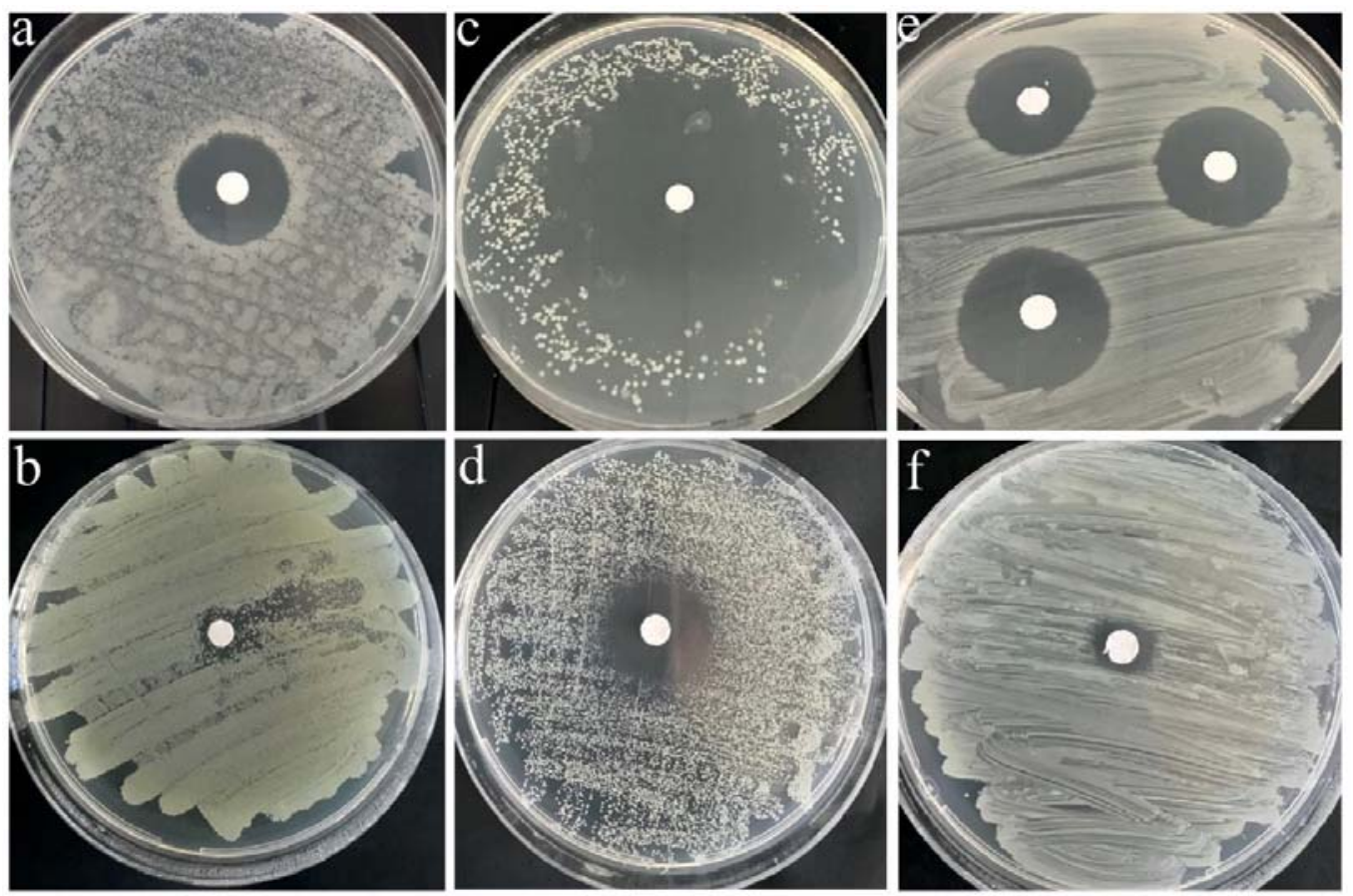

Fig. 2 - The images of inhibition zones of $15 \mu \mathrm{L} C s \mathrm{EO}$ (pure) and antibiotics against E. coli, S. aureus and C. albicans. a: E. coli for AMP, b: E. coli for $C s \mathrm{EO}$, c: C. albicans for FLC, d) C. albicans for $C s \mathrm{EO}$, e: $S$. aureus for AMP, f: $S$. aureus for $C s \mathrm{EO}$. 
Table 2

MICs $(\mu \mathrm{g} / \mathrm{mL})$ and FICIs of combinations of $C s E O(3.5 \mathrm{mg} / \mathrm{mL})$ with antibiotics $(128 \mu \mathrm{g} / \mathrm{mL}$ AMP or $5128 \mu \mathrm{g} / \mathrm{mL}$ FLC) and MICs values of $C s$ EO and antibiotics alone and IZs $(\mathrm{mm})$ of $C s E O$ (pure), AMP $(128 \mu \mathrm{g} / \mathrm{mL})$ on E. coli, S. aureus and FLC $(5128 \mu \mathrm{g} / \mathrm{ml})$ on C. albicans

\begin{tabular}{|c|c|c|c|c|c|c|}
\hline & \multicolumn{2}{|c|}{ E. coli } & \multicolumn{2}{|c|}{ S.aureus } & \multicolumn{2}{|c|}{ C. albicans } \\
\hline IZ $C s E O \rightarrow$ & \multicolumn{2}{|c|}{3.4} & \multicolumn{2}{|c|}{3.3} & \multicolumn{2}{|c|}{8.3} \\
\hline \multirow[t]{2}{*}{ IZ control $\rightarrow$} & \multicolumn{2}{|c|}{6.8} & \multicolumn{2}{|c|}{9.9} & \multicolumn{2}{|c|}{27} \\
\hline & MIC & FICI & MIC & FICI & MIC & FICI \\
\hline Ad & $152.06^{\mathrm{b}} \pm 3.1$ & - & $27.07^{\mathrm{c}} \pm 16.4$ & - & $26.74 \pm 11.9$ & - \\
\hline CsEOd & $479.26 \pm 30.4$ & - & $20.0^{\mathrm{ac}} \pm 8.4$ & - & $54.41 \pm 12.9$ & - \\
\hline $\mathrm{Ad}+C s \mathrm{EO}_{100}$ & $346.11 \pm 26.1$ & $2.9 \mathrm{IndE}$ & $298.08 \pm 26.7$ & $25.91 \mathrm{AntE}$ & $50.5 \pm 32.3$ & $2.8 \mathrm{IndE}$ \\
\hline $\mathrm{Ad}+C s \mathrm{EO}_{50}$ & $126.82^{\mathrm{b}} \pm 11.1$ & $1.09 \operatorname{lnd} \mathrm{E}$ & $134.03 \pm 21.3$ & 11.65 AntE & $34.24 \pm 19.2$ & $1.9 \mathrm{IndE}$ \\
\hline $\mathrm{Ad}+C s \mathrm{EO}_{25}$ & $369.79 \pm 38.3$ & $3.2 \mathrm{IndE}$ & $111.50 \pm 14.3$ & 9.69 AntE & $27.23 \pm 12.08$ & $1.5 \mathrm{IndE}$ \\
\hline $\mathrm{Ad}+C s \mathrm{EO}_{12.5}$ & $829.61 \pm 25.4$ & 7.1 AntE & $312.13 \pm 22.4$ & 27.14 AntE & $34.86 \pm 12.1$ & $1.9 \mathrm{IndE}$ \\
\hline $\mathrm{Ad}+C s \mathrm{EO}_{6.25}$ & $850.55 \pm 63.2$ & 7.3 AntE & $217.41 \pm 15.1$ & 18.91 AntE & $50.94 \pm 32.3$ & $2.8 \mathrm{IndE}$ \\
\hline $\mathrm{Ad}+C s \mathrm{EO}_{3.12}$ & $778.78 \pm 44.0$ & 6.7 AntE & $228.15 \pm 18.4$ & $2.45 \mathrm{IndE}$ & $53.62 \pm 16.9$ & $2.9 \mathrm{IndE}$ \\
\hline $\mathrm{Ad}+C s \mathrm{EO}_{1.56}$ & $1018.53 \pm 29.7$ & 8.8 AntE & $699.36 \pm 46.5$ & 60.80 AntE & $46.49 \pm 17.8$ & $2.5 \mathrm{IndE}$ \\
\hline
\end{tabular}

Statistically, a, b and c demonstrate the difference from the $\left(\mathrm{Ad}+C s \mathrm{EO}_{6.25}\right)$ fraction in $S$. aureus, the $\left(\mathrm{Ad}+C s \mathrm{EO}_{1.56}\right)$ fraction in E. coli and the $\left(\mathrm{Ad}+C s \mathrm{EO}_{1.56}\right)$ fraction in $S$. aureus, respectively. $\mathrm{n}=3$, d:dilution.

According to broth microdilution method, MICs on microorganisms of $C s \mathrm{EO}$ were found to be $479.26 \mu \mathrm{g} / \mathrm{mL}$ for E. coli, $20.0 \mu \mathrm{g} / \mathrm{mL}$ for $S$. aureus and $54.41 \mu \mathrm{g} / \mathrm{mL}$ for C. albicans while the MICs of antibiotics results were $152.06 \mu \mathrm{g} / \mathrm{mL}$, $27.07 \mu \mathrm{g} / \mathrm{mL}$ and $26.74 \mu \mathrm{g} / \mathrm{mL}$ for E. coli, $S$. aureus and C. albicans, respectively (Table 2).

When the combined antimicrobial activities of $C s E O$ and antibiotics were examined, the values of the MICs in all combinations were found to be statistically different $(p \leq 0.05)$ from the MICs determined from $C s \mathrm{EO}$ alone against pathogen microorganisms. The study of combination on $E$. coli showed that the highest efficacy was found with MIC of $152.06 \mu \mathrm{g} / \mathrm{mL}$ in the antibiotic alone, while the lowest efficacy was 1018.53 $\mu \mathrm{g} / \mathrm{mL}$ in the fraction of $\mathrm{Ad}+C s \mathrm{EO}_{1.56}$. On $S$. aureus, the highest efficacy was found with MIC of $20.0 \mu \mathrm{g} / \mathrm{mL}$ in $C s \mathrm{EO}$ alone, while the lowest efficacy was $699.36 \mu \mathrm{g} / \mathrm{mL}$ in the fraction of $\mathrm{Ad}+C s \mathrm{EO}_{1.56}$. Finally, on C. albicans, the highest efficacy was MIC of $26.74 \mu \mathrm{g} / \mathrm{mL}$ in $C s E O$ alone, while the lowest efficacy MIC was 54.41 $\mu \mathrm{g} / \mathrm{mL}$ in $C s \mathrm{EO}$ alone (Table 2).

The interaction data in the form of the FICI, exposing bacteria to CsEO-Ad combinations overnight, AntE and IndE effects occurred as $57.14 \%$ and $42.86 \%$ for E. coli, $14.29 \%$ and $85.71 \%$ S. aureus, respectively. Remarkable IntE action was observed against $C$. albicans (FICI: $100 \%$ ) by the combination of CsEO*FLC. Interestingly, no synergy was noted between $C s \mathrm{EO}$ and antibiotic combinations against microorganisms (FICIsyn:0) as shown in Figure 3. This might be attributed to the fact that the antibiotics are more powerful than $C s \mathrm{EO}$ against microorganisms.

Recent studies revealed the antimicrobial activity of the essential oils of Citrus species and their combination with antibiotics. ${ }^{30-35}$

Many terpene compounds such as limonene, thymol, linalool, eugenol, vanillin, citral have been accepted as preservatives and flavorings in the food industry by the European Commission. Besides, they are marked as GRAS (generally recognized as safe) in the United States Food and Drug Administration (FDA). ${ }^{36}$ However, some limitations on their use were introduced because of their interaction with food components which reduces their antimicrobial effectiveness. ${ }^{37}$ In our study, we showed that $C$. sinensis essential oil reduced the antibacterial effect by competing with ampicillin, especially against $E$. coli. 


\section{AntE $\approx$ IndE $\approx$ SynE}

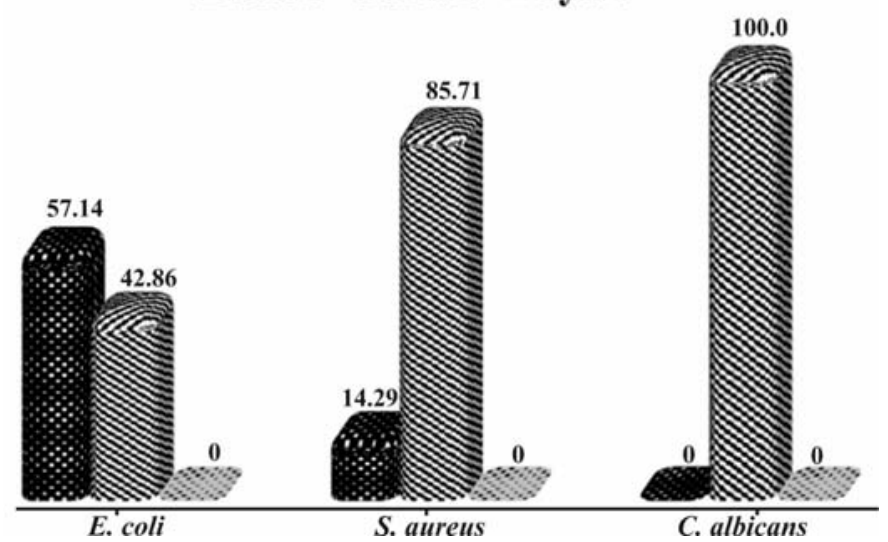

Fig. 3 - Percentage of FICI values of antibiotics and C. sinensis EO combinations against E. coli, S. aureus and C. albicans. Antagonistic: AntE, synergistic: SynE, Indifferent: IndE.
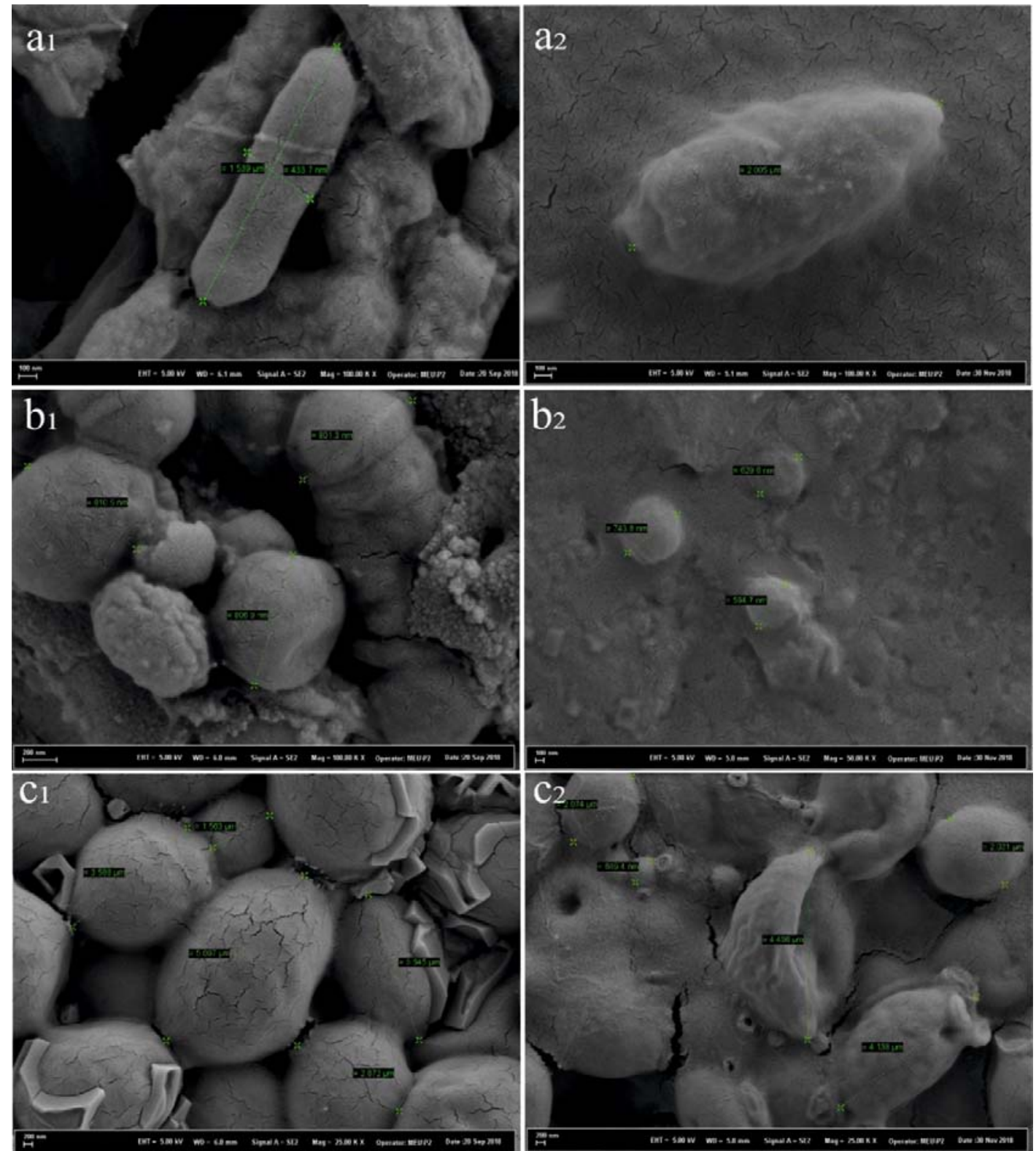

Fig. 4 - Representative SEM images of attached E. coli $\left(\mathrm{a}_{1}\right)$, S. aureus $\left(\mathrm{b}_{1}\right)$ and C. albicans $\left(\mathrm{c}_{1}\right)$ taken from non-treated and incubated with $C S E O$ and E. coli $\left(\mathrm{a}_{2}\right)$, S. aureus $\left(\mathrm{b}_{2}\right)$ and C. albicans $\left(\mathrm{c}_{2}\right)$, respectively, after $24-\mathrm{h}$ incubation. 


\section{SEM Images of Microorganisms Treated with $C s E O$}

SEM micrographs of E. coli, S. aureus and C. albicans in the presence of $C s \mathrm{EO}$ were pointed out that morphological changes do occur in the microorganisms' surfaces. Similar observations have been made with Enterococcus species in the presence of citrus EOs. ${ }^{38}$

Changes in the cell morphology were observed in high magnification SEM images (Figure 4). Figures $4\left(\mathrm{a}_{1}, \mathrm{~b}_{1}\right.$, and $\left.\mathrm{c}_{1}\right)$ shows untreated E. coli, $S$. aureus and $C$. albicans, respectively while figures $4\left(\mathrm{a}_{2}, \mathrm{~b}_{2}\right.$, and $\left.\mathrm{c}_{2}\right)$ shows incubated $E$. coli, S. aureus and $C$. albicans with $C s \mathrm{EO}$, respectively. When treated with $C s \mathrm{EO}$, morphological deterioration of the cell surface was observed. A spreading pattern change was seen on cell surfaces on $E$. coli and $S$. aureus matrix, whereas an intracellular collapse in $C$. albicans. In particular, the swelling and expansion in $E$. coli were quite remarkable. These changes may occur due to differences in cell wall structures of microorganisms.

\section{CONCLUSIONS}

Many of the compounds ( $\alpha$-pinene, $\beta$-myrcene, sabinene, linalool, 4-terpineol, $\alpha$-terpineol, carvacrol, $d$-limonene, geraniol, nerol and $p$-vinylguaiacol) detected in $C s \mathrm{EO}$ as a result of GC-MS analysis were determined to show antimicrobial activity or contribute to the total antimicrobial activity of the essential oil compared to literature data. In particular, it can be argued that d-limonene plays a major role in antimicrobial activity. This was supported by the results of the antimicrobial activity results obtained in this study. The antimicrobial effect of $C$. sinensis essential oil was updated by both disc diffusion and microdilution method. The most important emphasis here is the interaction with antibiotics. This paper provided an example of indifferent and antagonist effect interactions of $C$. sinensis EO and antibiotic combinations against E. coli, $S$. aureus and C. albicans microorganisms. Since the target of both antibiotics and essential oils is primarily cell wall destruction, it is predictable that there will be competition between them. The most important result from the study suggests that $C$. sinensis decreased antibiotic activity on bacteria by competing with ampicillin antibiotic. Compounds exist in the essential oil of $C$. sinensis often show antagonistic effects on microorganisms, meaning that the antibiotic will partially slow down its effectiveness. This may also slow the resistance to antibiotics. Thus, essential oil drug interactions can shed light on us to prevent and/or understand the resistance that occurs in this time frame.

Acknowledgements. This study was supported by Mersin University Scientific Research Projects Unit. Project no: 20182-AP3-2939.

\section{REFERENCES}

1. S. Shetty, P. Mahin-Syed-Ismail, S. Varghese, B. ThomasGeorge, P. Kandathil- Thajuraj, D. Baby, S. Haleem, S. Sreedhar and D. Devang-Divakar, J. Clin. Exp. Dent., 2016, 8,71 .

2. L. Abbate, N. Tusa, S. Fatta Del Bosco, T. Strano, A. Renda and G. Ruberto, Food Res. Int., 2012, 48, 284.

3. Y. Matsuo, L. A. Miura, T. Araki and Y. Yoshie-Stark, Food Chem., 2019, 279, 356.

4. J. Favela-Hernández, O. González-Santiago, M. RamírezCabrera, P. Esquivel-Ferriño and M. Camacho-Corona, Molecules, 2016, 21, 247.

5. H. Kelebek and S. Selli, J. Sci. Food Agric., 2011, 91, 1855.

6. L. Espina, M. Somolinos, S. Lorán, P. Conchello, D. García and R. Pagán, Food Control, 2011, 22, 896.

7. G. Zhou, Q.-S. Shi, X.-M. Huang and X.-B. Xie, IJMS, 2015, 16, 21711.

8. D. Predoi, S. Iconaru, N. Buton, M. Badea and L. Marutescu, Nanomaterials, 2018, 8, 291.

9. O. Nitzan, U. Suponitzky, Y. Kennes, B. Chazan, R. Raz and R. Colodner, 2010, 12, 4.

10. P. S. Ocampo, V. Lázár, B. Papp, M. Arnoldini, P. Abel zur Wiesch, R. Busa-Fekete, G. Fekete, C. Pál, M. Ackermann and S. Bonhoeffer, Antimicrob. Agents Chemother., 2014, 58, 4573.

11. T. Stergiopoulou, J. Meletiadis, T. Sein, P. Papaioannidou, I. Tsiouris, E. Roilides and T. J. Walsh, J. Antimicrob. Chemother., 2008, 63, 343.

12. F. C. Odds, J. Antimicrob. Chemother., 2003, 52, 1.

13. M. M. Harriott and M. C. Noverr, Antimicrob. Agents Chemother., 2009, 53, 3914.

14. İ. Tegin, E. Yabalak, B. Sadı, M. Fidan, B. Sadik and M. Fidan Rev. Roum. Chim., 2019, 64, 673.

15. E. Yabalak, J. Turkish Chem. Soc. Section A: Chem., 2017, 5, 205.

16. E. Yabalak, F. Ibrahim, E.A. Erdoğan Eliuz, A. Everest, A.M. Gizir, Plant Biosyst. 2021, In press, https://doi.org/10.1080/11263504.2020.1852332

17. Lj. Vujisić, I. Vučković, V. Tešević, D. Đoković, M. S. Ristić, P. Janaćković and S. Milosavljević, Flavour Fragr. J., 2006, 21, 458.

18. V. Saroglou, P. D. Marin, A. Rancic, M. Veljic and H. Skaltsa, Biochem Syst Ecol, 2007, 35, 146.

19. M. Jalali-Heravi, B. Zekavat and H. Sereshti, J Chromatogr A, 2006, 1114, 154.

20. E. Yabalak, Z. Emire. A.O. Adigüzel, S. Könen Adıgüzel, A..M. Gizir, Flavour Fragr J. 2020, 35, 394.

21. M. Hazzit, A. Baaliouamer, M. L. Faleiro and M. G. Miguel, J. Agric. Food Chem., 2006, 54, 6314. 
22. M. J. Velázquez-Nuñez, R. Avila-Sosa, E. Palou and A. López-Malo, Food Control, 2013, 31, 1.

23. P. Singh, R. Shukla, B. Prakash, A. Kumar, S. Singh, P. K. Mishra and N. K. Dubey, Food Chem. Toxicol., 2010, 48, 1734

24. K. K. Aggarwal, S. P. S. Khanuja, A. Ahmad, T. R. Santha Kumar, V. K. Gupta and S. Kumar, Flavour Fragr. J., 2002, 17, 59.

25. N. Chorianopoulos, E. Evergetis, A. Mallouchos, E. Kalpoutzakis, G.-J. Nychas and S. A. Haroutounian, J. Agric. Food Chem., 2006, 54, 3139.

26. B. Tohidi, M. Rahimmalek, A. Arzani and M. R. Sabzalian, Food Chem., 2020, 307, 125521.

27. W. A. Asuming, P. S. Beauchamp, J. T. Descalzo, B. C. Dev, V. Dev, S. Frost and C. W. Ma, Biochem. Syst. Ecol., 2005, 33, 17.

28 G. Sacchetti, S. Maietti, M. Muzzoli, M. Scaglianti, S. Manfredini, M. Radice and R. Bruni, Food Chem., 2005, 91,621 .

29. M. Küçük, C. Güleç, A. Yaşar, O. Üçüncü, N. Yaylı, K. Coşkunçelebi, S. Terzioğlu and N. Yayl, Pharm. Biol., 2006, 44, 592.
30. N. Tao, Y. Liu and M. Zhang, Int. J. Food Sci., 2009, 44, 1281.

31. S. Chanthaphon, S. Chanthachum and T. Hongpattarakere, Songklanakarin J. Sci. Technol., 2008, 7.

32. N. J. Ruiz-Pérez, M. González-Ávila, J. SánchezNavarrete, J. D. Toscano-Garibay, M. A. MorenoEutimio, T. Sandoval-Hernández and M. Arriaga-Alba, Sci. Rep., 2016, 6, 25371.

33. K. Fisher and C. Phillips, Br. J. Biomed. Sci., 2009, 66, 180.

34. S. de Rapper, G. Kamatou, A. Viljoen and S. van Vuuren, Evid--Based Complementary Altern. Med., 2013, 2013, 1.

35. L. Settanni, E. Palazzolo, V. Guarrasi, A. Aleo, C. Mammina, G. Moschetti and M. A. Germanà, Food Control, 2012, 26, 326.

36. M. Hyldgaard, T. Mygind and R. L. Meyer, Front. Microbio., 2012, 3.

37. R. M. Cava-Roda, A. Taboada-Rodríguez, M. T. Valverde-Franco and F. Marín-Iniesta, Food Bioprocess Technol., 2012, 5, 2120.

38. K. Fisher and C. Phillips, Trends Food Sci. Tech., 2008, $19,156$. 
